\title{
Optimizing collaborative relationships in emergency medicine research
}

\author{
Jeffrey J. Perry ${ }^{1,2}$ (1) $\cdot$ Christian Vaillancourt ${ }^{1,2} \cdot$ Corinne M. Hohl $^{3} \cdot$ Venkatesh Thiruganasambandamoorthy $^{1,2}$. \\ Judy Morris ${ }^{4} \cdot$ Marcel Emond ${ }^{5,6} \cdot$ Jacques Lee $^{7,8} \cdot \operatorname{lan}$ G. Stiell ${ }^{1,2}$
}

Received: 18 December 2020 / Accepted: 24 December 2020 / Published online: 18 February 2021

(c) The Author(s), under exclusive licence to Canadian Association of Emergency Physicians (CAEP)/ Association Canadienne de Médecine d'Urgence (ACMU) 2021

\begin{abstract}
Objective The objective of the Canadian Association of Emergency Physicians (CAEP) 2020 Academic Symposium Panel was to present recommendations for collaboration on (1) writing a grant application; (2) conducting a study; (3) writing an abstract; and (4) writing a manuscript.

Methods We assembled an expert panel of eight experienced emergency medicine clinician scientists from across Canada. Panel members performed literature searches for each of the four topics. Draft recommendations were developed and refined in an iterative fashion by panel members. We solicited external feedback on the draft recommendations online from identified researchers known to CAEP and in person at the Network of Canadian Emergency Researchers meeting in February 2020. We obtained additional feedback during an online symposium presentation on October 15th, 2020, open to all members of the Canadian Association of Emergency Physicians.

Results Four sets of recommendations were established for each component including: 14 for writing a grant application including relevant timelines; 23 for conducting a study; 13 for writing an abstract; and 18 for writing a manuscript. Forming a strong team, including patients, appropriate methodologists, content experts and a mix of senior and junior investigators, establishing and following clear timelines, and proactive communications were common themes.

Conclusions We offer recommendations for research collaboration for (1) writing a grant, (2) conducting a study, (3) writing an abstract, and (4) writing a manuscript. We believe these recommendations will help to improve the science, improve grant success, and improve the impact of the abstracts and manuscripts.
\end{abstract}

Keywords Emergency medicine $\cdot$ Collaboration $\cdot$ Research

\section{Résumé}

Objectif L'objectif du comité d'experts du symposium académique 2020 de l'Association canadienne des médecins d'urgence (ACMU) était de présenter des recommandations de collaboration sur (1) la rédaction d'une demande de subvention; (2) l'accomplissement d'une étude; (3) la rédaction d'un résumé; et (4) la rédaction d'un manuscrit.

Jeffrey J. Perry

jperry@ohri.ca

1 Department of Emergency Medicine, University of Ottawa, Ottawa, ON, Canada

2 Clinical Epidemiology Program, Ottawa Hospital Research Institute, Ottawa, ON, Canada

3 Department of Emergency Medicine, University of British Columbia, Vancouver, BC, Canada

4 Department of Family Medicine and Emergency Medicine, Université de Montréal, Montréal, QC, Canada
5 CHU de Québec, Hôpital de l'Enfant-Jésus, Québec City, Québec, Canada

6 Division of Emergency Medicine, Université Laval, Québec City, Québec, Canada

7 SchwartzlReisman Emergency Medicine Institute, Mount Sinai Hospital, Toronto, ON, Canada

8 Department of Emergency Medicine, Sunnybrook Health Sciences Centre, Toronto, ON, Canada 
Méthodes Nous avons réuni un comité d'experts de huit cliniciens-chercheurs en médecine d'urgence dotés d'expérience de partout au Canada. Les membres du comité ont effectué des recherches documentaires sur chacun des quatre sujets. Des projets de recommandations ont été élaborés et affinés de manière itérative par les membres du comité. Nous avons sollicité en ligne des remarques externes sur les projets de recommandations des chercheurs connus de l'ACMU (CAEP) ainsi que des chercheurs connus en personne lors de la réunion du Réseau des chercheurs d'urgence canadienne en février 2020. Nous avons obtenu des remarques supplémentaires lors d'une présentation du symposium en ligne le 15 octobre 2020, ouvert à tous les membres de l'Association canadienne des médecins d'urgence.

Résultats Quatre séries de recommandations ont été établies pour chaque composante, dont: 14 pour la rédaction d'une demande de subvention, y compris les délais pertinents; 23 pour mener une étude; 13 pour rédiger un résumé; et 18 pour la rédaction d'un manuscrit. La formation d'une équipe solide, comprenant des patients, des méthodologistes appropriés, des experts en contenu et un mélange de chercheurs principaux et chercheurs assistants, l'établissement et le respect de calendriers clairs et des communications proactives étaient des thèmes communs.

Conclusion Nous proposons des recommandations de collaboration de recherche pour (1) rédiger une subvention, (2) mener une étude, (3) rédiger un résumé et (4) rédiger un manuscrit. Nous croyons que ces recommandations contribueront à améliorer la science, à renforcer le succès des subventions et à bonifier l'impact des résumés et des manuscrits.

\section{Introduction}

\section{Background}

Emergency medicine research is an evolving field in Canada. Although clinician researchers are relatively few, a growing number of emergency departments (ED) and university ED programs have clinician scientists conducting research [1]. Many of these scientists are highly prolific and are creating practice changing research. However, clinician scientists benefit from collaborative efforts. The collective experience of EM clinician scientists and the formation of the research networks within emergency medicine (e.g. Network of Emergency Researchers (NCER), Pediatric Emergency Research Consortium (PERC), Canadian Resuscitation Outcomes Consortium (CanROC), etc.) signal that emergency medicine research has reached a level of maturity required to conduct multicentre studies. Multicentre studies provide better evidence and are more likely to get funded. We lack a framework to optimize collaborative efforts to facilitate successful multicentre, multidisciplinary studies.

There is very little literature on how best to collaborate with others when writing grants, abstracts, manuscripts and conducting multicentre studies. There is a clear gap in guidance for investigators interested in collaborating. This paper reviews the recommendations from the 2020 Canadian Association of Emergency Physicians (CAEP) Academic Symposium Panel: How to Optimize Collaborative Relationships in Emergency Medicine Research. The target audience of these recommendations includes clinical researchers of all levels of experience, their research teams and collaborators.

\section{Objectives}

We sought to identify how best to collaborate when (1) leading a team to write a successful grant application; (2) conducting a study; (3) writing a scientific abstract; and (4) writing a manuscript.

\section{Methods}

We assembled an expert panel of eight emergency medicine clinician scientists with extensive research experience from across Canada. We selected clinician scientists from the 3 largest Canadian provinces with more than 10 years experience and research training. The expert panel consisted of 25\% women, 25\% Certification in the College of Family Physicians-Emergency Medicine [CCFP(EM)] certification versus 75\% Fellow of the Royal College of Physicians of Canada-Emergency Medicine [FRCPC(EM)] and all from academic centres.

Panel members performed literature searches for each of the four topics. Draft recommendations were developed and refined in an iterative fashion by panel members using a combination of conference calls and email. We sought external feedback on the recommendations from identified researchers across Canada and in person at the NCER conference at Lake Louise, Alberta, in February 2020. At the NCER conference, we obtained feedback from clinical researchers, research coordinators and research assistants. Additional feedback was sought during an online symposium, open to all members of CAEP in October 2020. The proposed four best practice lists were finalized after incorporating this feedback. 


\section{Recommendations}

\section{Box 1. Writing a grant [2]}

- A systematic review, survey and pilot data for the project objective will improve chances of success and are often considered a pre-requisite for Canadian Institutes of Health Research (CIHR) and other large granting agencies

- Assemble a strong team including patients, senior scientists, biostatistician, and applicable clinical and methodological specialists to the area of the study

- Applying for targeting opportunities often have higher success rates. You may need to be strategic and start small and grow the study with additional funding as it becomes available. Applying to multiple agencies with the same grant (adapted for the style of the given agency) is encouraged

- Get a mentor and use a template of a similar previously funded study before you start writing

- Make the grant easy to read, understandable and error free. Verify that a smart person, with no background knowledge of the grant, can understand it. Ideally, do not use any abbreviations, especially nonstandard abbreviations

- Study rationale must be compelling

- The lay and scientific summaries are usually the first documents read. Ensure these are well prepared and fully reviewed by study team

- Ensure that institutional representative(s) have been notified of intent to submit grant. If internal deadline is earlier than granting agency deadline, all above dates should use this internal deadline as the date of submission

- Reassess progress against planned submission milestones every 2 weeks

- Support letters are only helpful if they clearly demonstrate the value added by the site. Standardized letters are not helpful and make it harder for reviewers to locate documents

-While the budget is supposed to be reviewed separately from the science, try to ensure that you do not ask for too much, just enough to do the study with a plan to adjust for a possible $20 \%$ reduction in budget. Ensure budget is well justified

- If granting agency does not communicate directly with all authors, forward the decision response to them; if a rejection, discuss possible revisions and new plan

- Grants often do not get funded on the first submission, so even after submission, try to take steps to improve the proposal while waiting on the funding assessment (e.g. conduct a survey, systematic review, or get pilot data if these steps have not been done at the time of initial submission)

- If accepted, provide letter and approximate timeline to start project with planned next steps to co-applicants

\begin{tabular}{|c|c|}
\hline \multicolumn{2}{|l|}{ Suggested timelines } \\
\hline Time before submission & Action \\
\hline 6 months & Assemble core team members* \\
\hline 3 months & $\begin{array}{l}\text { Finish writing initial draft one- } \\
\text { page summary }\end{array}$ \\
\hline 3 months & $\begin{array}{l}\text { Principal applicant to recruit any } \\
\text { remaining sites/co-investigators }\end{array}$ \\
\hline 3 months & $\begin{array}{l}\text { Clarify all roles and responsi- } \\
\text { bilities including a checklist of } \\
\text { actions needed/timelines }\end{array}$ \\
\hline 2 months & $\begin{array}{l}\text { If possible, submit to REB at the } \\
\text { PI's institution }\end{array}$ \\
\hline 2 months & $\begin{array}{l}\text { Finish writing draft protocol in } \\
\text { its entirety, or in small sections } \\
\text { (e.g. objectives, methods, back- } \\
\text { ground) }\end{array}$ \\
\hline 2 months & $\begin{array}{l}\text { Confirm who is collecting and } \\
\text { coordinating the CVs, PINs, } \\
\text { confirm affiliations from all co- } \\
\text { applicants and start requesting } \\
\text { these. Absolute deadline for } \\
\text { these should be } 2 \text { weeks prior to } \\
\text { submission }\end{array}$ \\
\hline 1.5 months & $\begin{array}{l}\text { Identify staff to create budget } \\
\text { and budget justification. Draft } \\
\text { budget should be reviewed by } \\
\text { core team members. Ensure } \\
\text { the budget will cover costs yet } \\
\text { remains "fundable". Once draft } \\
\text { solidified, start budget justi- } \\
\text { fication. Both to be complete } \\
2 \text { weeks prior to submission }\end{array}$ \\
\hline $\begin{array}{l}1.5 \text { months (confirm your local } \\
\text { deadline) }\end{array}$ & $\begin{array}{l}\text { Submit draft protocol for internal } \\
\text { review by university or col- } \\
\text { leagues previously funded by the } \\
\text { same agency for critical review } \\
\text { and feedback }\end{array}$ \\
\hline 1.5 months & $\begin{array}{l}\text { Identify which letters of support } \\
\text { are needed (usually one per site } \\
\text { and at least one national organi- } \\
\text { zation (e.g. CAEP). Identify } \\
\text { who will coordinate collecting } \\
\text { these. Usually best to have PI } \\
\text { request the document and ask } \\
\text { that these be sent to the staff } \\
\text { designated by } 1 \text { month prior to } \\
\text { submission. Reminders should } \\
\text { be sent as needed to ensure all } \\
\text { letters are received by } 2 \text { weeks } \\
\text { prior to submission. Prepare } \\
\text { draft letters of support to be } \\
\text { provided to the letter writers to } \\
\text { modify }\end{array}$ \\
\hline
\end{tabular}




\begin{tabular}{|c|c|}
\hline \multicolumn{2}{|l|}{ Suggested timelines } \\
\hline Time before submission & Action \\
\hline 1 month & $\begin{array}{l}\text { Send all revised documents to co- } \\
\text { applicants including one-page } \\
\text { summary, lay summary, reply to } \\
\text { prior submission (if applicable) } \\
\text { and main protocol/appendices } \\
\text { and ask for feedback within } \\
10 \text { days; provide a reminder } \\
\text { after } 1 \text { week }\end{array}$ \\
\hline 1 month & $\begin{array}{l}\text { Obtaining internal signatures } \\
\text { should be delegated to staff, } \\
\text { to determine who will sign } \\
\text { (i.e. usual signing authority } \\
\text { or delegate). Confirm if it is } \\
\text { University or Research Institute } \\
\text { who signs. Department Head } \\
\text { signature is also required. All } \\
\text { local co-investigators should } \\
\text { ideally sign the same form }\end{array}$ \\
\hline Submission & $\begin{array}{l}\text { Ensure all members of the team } \\
\text { get a copy of the entire submis- } \\
\text { sion and notification that it was } \\
\text { successfully submitted on time }\end{array}$ \\
\hline \multicolumn{2}{|c|}{$\begin{array}{l}\text { *Core team members should include senior researchers, junior } \\
\text { researchers, statistician, pertinent specialists (e.g. neurology, } \\
\text { geriatrics, cardiology, psychologist, KT expert), patient partner. } \\
\text { Roles and time commitments from core team members should } \\
\text { be discussed and clarified early. Ideally, experienced investiga- } \\
\text { tors and departments can provide administrative support for this } \\
\text { process. Core team members build the preliminary protocol and } \\
\text { discuss how to broaden/build the team. As the team is broadened, } \\
\text { include all additional members on all correspondence }\end{array}$} \\
\hline
\end{tabular}

$\mathrm{REB}=$ Research Ethics Board; $\mathrm{PI}=$ principal investigator; $\mathrm{CV}=$ curriculum vitae; PINs $=$ personal identification number; $\mathrm{CAEP}=$ Canadian Association of Emergency Physicians; KT expert $=$ knowledge translation expert.

\section{Box 2. Conducting a study}

- Inform investigators and grants officer that grant application was successful

- Update budget and study based on funding received

- Draft job description, post position and hire new staff if required-consider sharing human resources with other investigators or between projects

- Plan physical space and equipment for new staff-plan ahead if need for specialized equipment

- Create and ensure all study personnel are familiar with standard operating procedures and documents for study

- Complete a "delegation of task document" for study
- Re-engage/conference call with investigators/sites who provided support for application

- Collect co-investigators' updated CVs and confirm completion of TCPS2 when relevant

- Form Study Committees and draft Terms of References (steering, publication, public, paramedic, DSMB, etc.)

- Revise and update the study protocol as needed, (https ://www.spirit-statement.org/) [3] develop a study manual, teaching materials, study materials, and distribute for comments from investigators and coordinating staff

- Finalize above documents and register study

- Submit for ethics review if not done at grant application stage. Consider centralized ethics submission or a structure where one site in the province can act as provincial coordinating site for ease of ethics approval (e.g. Clinical Trials Ontario: https://www.ctontario. $\mathrm{ca} /)$

- Inform contract officer and share study documents, draft and distribute Data Sharing Agreements and contracts

- Wait for institutional approval before proceeding

- Communicate clearly with sites proposed start date, any cross-over dates if applicable well in advance

- Receive, process, invoice, pay for services in accordance with contracts and agreements

- Hold regular and interim Steering Committees and distribute minutes

- Draft and distribute Newsletters and/or engage in other social media/study website

- Keep track of renewal deadlines (ethics) and update study registry when required

- Prepare interim reports (funding agencies, DSMB, staff evaluations) when required

- Inform stakeholders about study completion (sites, ethics, registration, etc.)

- Inform statistician ahead of study completion and start cleaning database(s) for linkage with other databases and analysis

- Make plans for disposal/storage of study material

$\mathrm{CV}=$ curriculum vitae; TCPS2 $=$ Tri-Council Policy Statement (2018); DSMB = Data Safety and Monitoring Board.

\section{Box 3. Writing an abstract [2]}

- Presenting and publishing a conference abstract provides an opportunity for consolidating and interpreting results, getting peer feedback prior to publication and publication of the abstract. 
- Inform investigators at least 1 month before the deadline of the intent to submit an abstract.

- If unable to include all authors in the abstract due to restrictions, explain rationale for inclusion of those selected.

- Provide a draft of the abstract and pertinent results output from the data and circulate it at least 2 weeks before the abstract deadline.

- Co-authors to provide feedback within 5 days of receipt.

- Second draft to be circulated if needed at least 1 week before the abstract deadline.

- Send the final version of the abstract to all the coauthors.

- Once selected for presentation, inform all the coauthors.

- If the abstract is published in a journal, provide a copy of the published abstract and citation details to all the co-authors.

- Request names for acknowledgement from all the study sites and site PIs for inclusion in the presentation.

- Circulate the presentation/poster at least 3 weeks before the presentation date for comments.

- Once the presentation is complete, communicate to all co-authors regarding feedback at the conference.

-Incorporate the feedback in the manuscript.

\section{Box 4. Writing a manuscript [4-7]}

- Indicate intent to write manuscript and confirm coauthors as early as possible; all authors must meet the ICMJE criteria [8]; no honorary authorship.

- Inform investigators once results are available and provide preliminary tables as soon as possible; discuss interpretation and focus of the paper by email or conference call.

- Start discussion of target journal.

- If available, solicit assistance for the methods and results section from a statistician or someone with statistical expertise.

- Review complete draft with a senior mentor/colleague prior to circulating.

- Circulate a complete draft to all authors and ask for feedback within a set deadline (e.g. 14 days; provide a reminder a few days before the deadline).

- Revise according to feedback and then circulate a tracked changes version for all authors to review.

- Further revisions may be required until all authors have signed off on the paper.

- Ask authors to update their affiliations.
- Confirm the first target journal.

- Review instructions for authors for that journal, requirements for cover letter, and format/word count for abstract.

- Consider use of a staff member to oversee formatting and submission.

- Submit to journal and ensure all authors are aware and have the final clean version.

- If journal does not communicate directly with all authors, forward the decision response to them; if a rejection, discuss possible revisions and next target journal.

- If revise and resubmit, circulate draft revisions and responses for comment and approval several weeks prior to the deadline.

- Circulate proofs to all authors so they can review their names and affiliations.

- Ensure all authors are aware of publication date and any press releases prepared by your institution or the journal.

- Provide pdf of final published version to all authors as well as the citation for their CVs.

ICJME $=$ International Committee of Medical Journal Editors; $\mathrm{CV}=$ curriculum vitae.

\section{Conclusion}

Four sets of recommendations were established for each component including: 14 for writing a grant application including relevant timelines; 23 for conducting a study; 13 for writing an abstract; and 18 for writing a manuscript. Forming a strong team, including patients, appropriate methodologists, content experts and a mix of senior and junior investigators, establishing and following clear timelines, and proactive communications were common themes. We believe these recommendations will help to improve the science, improve grant success, and improve the impact of the abstracts and manuscripts.

Acknowledgements We appreciate all the clinicians, research coordinators and research assistants who provided feedback on the draft recommendations. Dr. Jeffrey Perry is supported by the Heart and Stroke Foundation of Ontario through a Mid-Career Award. Dr. Jacques Lee is supported by the Schwartz/Reisman Emergency Medicine Institute Inaugural Research Chair in Geriatric Emergency Medicine.

\section{References}

1. Stiell IG, Artz JD, Lang ES, et al. An environmental scan of academic emergency medicine at the 17 Canadian medical schools: why does this matter to emergency physicians? CJEM. 2017;19:39-46. 
2. Harvey BJ, Lang ES, Frank JR. The research guide: a primer for residents, other health care trainees, and practitioners. 1st ed. Ottawa: The Royal College of Physicians and Surgeons of Canada; 2011.

3. Chan AW, Tetzlaff JM, Altman DG, et al. SPIRIT 2013 statement: defining standard protocol items for clinical trials. Ann Intern Med. 2013;158:200-7.

4. Zhang XC, Tran AH, Papanagnou D. A curious researcher's guide on successfully publishing scientific manuscripts. Cureus. 2018;10:e2683.

5. Buderer NM, Plewa MC. Collaboration among emergency medicine physician researchers and statisticians: resources and attitudes. Am J Emerg Med. 1999;17:692-4.
6. Archer SW, Carlo WA, Truog WE, et al. Improving publication rates in a collaborative clinical trials research network. Semin Perinatol. 2016;40:410-7.

7. Pololi L, Knight S, Dunn K. Facilitating scholarly writing in academic medicine. J Gen Intern Med. 2004;19:64-8.

8. International Committee of Medical Journal Editors. Recommendations for the Conduct, Reporting, Editing and Publication of Scholarly Work in Medical Journals. 2020. 2020. 